\title{
Um prefácio imaginário para Thalassa
}

\author{
An imaginary prelude to Thalassa
}

Un prefacio imaginario en Thalassa

\section{Leonardo Cardoso Portela Câmara*}

Universidade Federal do Rio de Janeiro - UFRJ, Rio de Janeiro, Rio de Janeiro, Brasil

\section{Regina Herzog**}

Universidade Federal do Rio de Janeiro - UFRJ, Rio de Janeiro, Rio de Janeiro, Brasil

\begin{abstract}
RESUMO
Pretendemos realizar uma incursão pelas teses principais do polêmico 'Thalassa: ensaio sobre a teoria da genitalidade', obra de Sándor Ferenczi publicada em 1924. Considerado amiúde como um trabalho estranho e extravagante, propomos sua releitura a partir de uma hipótese: 'Thalassa' exige o abandono de formas habituais do pensar.

Palavras-chave: Ferenczi, catástrofe, utraquismo, filogênese, psicanálise.
\end{abstract}

\begin{abstract}
We intend to carry out an incursion through the main theses from the controversial 'Thalassa: a theory of genitality', a work by Sándor Ferenczi published in 1924. Often considered a strange and extravagant work, we propose a new reading, starting from a proposition: 'Thalassa' demands the abandonment of customary ways of thinking.

Keywords: Ferenczi, catastrophe, utraquismo, phylogenesis, psychoanalysis.

\section{RESUMEN}

Tenemos la intención de llevar a cabo una incursión por las principales tesis del polémico 'Thalassa, ensayo sobre la teoría de la genitalidad', obra de Sándor Ferenczi publicada en 1924. Considerado a menudo como un trabajo extraño y extravagante, se propone una nueva lectura a partir de una hipótesis: 'Thalassa' exige el abandono de las formas habituales de pensar.

Palabras clave: Ferenczi, catástrofe, utraquismo, filogénesis, psicoanálisis.
\end{abstract}

\section{Introdução}

Conta-se que um camponês meteu na cabeça que não havia mais campos além do seu. Mas uma de suas vacas desapareceu e, vendo-se obrigado a buscá-la longe, caiu em admiração quando viu que mais além de seus campos havia muitos outros. 
- Espinosa, Breve tratado.

Thalassa: ensaio sobre a teoria da genitalidade foi o terceiro livro de autoria individual ${ }^{1}$ publicado por Ferenczi na coleção "Biblioteca Psicanalítica Internacional". Apesar de ter sido escrito aos cinquenta anos de idade (1923) e de ter sido publicado no ano seguinte, as ideias principais deste ensaio remontam da época em que seu autor servia, como médico, ao exército durante a Primeira Guerra. Antes de assumir a diretoria de um hospital no qual entraria em contato com uma grande amostra de soldados impactados pela experiência da guerra, Ferenczi lançara-se, nos seus tempos de ócio, a traduzir os Três ensaios sobre a teoria da sexualidade para o húngaro e a ler alguns livros de que dispunha relacionados à temática da biologia (Ferenczi, 1924/1990). Essas duas atividades, conjugadas a um diálogo intenso e ao mesmo tempo constante com Freud, levaram-no a cultivar um hábito: anotar, em qualquer pedaço de papel ao seu alcance, ideias ou apontamentos que lhe acudissem e se relacionassem com um projeto que lentamente germinava em seu espírito.

Depois de um ano de acumulação de papeis e de ideias, surge um plano: escrever entre quinze e vinte "ensaios bioanalíticos" os quais versariam sobre problemas oriundos das mais diversas áreas clínica, vida cotidiana, psicanálise, biologia (Freud \& Ferenczi, 1996). Eles formariam um parentesco com os "ensaios metapsicológicos" que, na mesma época, se encontravam em processo de gestação em Freud. Se o projeto não foi para frente, ao menos deu espaço para outro, não menos ambicioso: escrever um livro que comportasse e unificasse as ideias de todos os ensaios bioanalíticos abortados. Em outras palavras, escrever um ensaio combinando, em sua unidade mesma, uma multiplicidade de pequenos ensaios que manteriam entre si relações orgânicas essenciais. No total, desde o surgimento das primeiras ideias até sua publicação, serão necessários nove anos para Ferenczi conseguir lançar seu livro. Após isso, ele viverá outros nove anos antes que uma doença, que arruinará progressivamente suas capacidades motoras, ceife sua vida.

Não dispomos de informações claras a respeito da recepção do livro no meio psicanalítico, mas lemos no comovente necrológio escrito por Freud (1933/2011) ao amigo falecido que Thalassa foi "sua realização mais brilhante, mais rica de ideias" (p. 467). Balint expõe, por sua vez, duas considerações interessantes: de um lado, que alguns personagens (encabeçados por Ernest Jones) consideraram Thalassa um sinal inequívoco de que Ferenczi começara a entrar em um processo psicótico - processo este que atingiria o paroxismo quando da sua postulação da teoria do trauma (Jones \& Balint, 2004); e, de outro lado, que o terceiro capítulo do livro, "O desenvolvimento do sentido de realidade erótica e seus estágios", pode ser apontado 
como o monumento que inaugura um novo paradigma ou uma nova orientação teórica em psicanálise, a saber, a teoria das relações objetais (Balint, 1967/2014). Essas duas posturas são emblemáticas no que se refere à reação que um leitor pode ter quando entra em contato com Thalassa: ou esta obra é desmentida e desqualificada, sendo considerada nada mais que uma aberração exagerada e sem sentido, ou, pelo contrário, é experienciada como um espaço com potencialidades imprevisíveis, sendo, neste sentido e nas palavras de Birman (2014), "uma peça única, merecedora de uma leitura sistemática e detalhada" (p. 37). Sabemos que a relação de Balint com Thalassa foi explicitamente marcada por esta segunda possibilidade de contato: os conceitos de falha básica e de thrilling são, por exemplo, tributários das figuras de catástrofe e de erotismo lúdico, ambas trabalhadas por Ferenczi nesse ensaio (Balint, 1967/2014; 1959/1987; Ferenczi, 1924/1990).

Seja como for, mesmo tentando encarar Thalassa de uma maneira mais neutra, quer dizer, ainda que sigamos a recomendação de Freud (1920/1940) e assumamos, com relação à obra, uma postura de "kühles Wohlwollen" (p. 65), de fria benevolência, não precisamos nos proibir de sentir estranheza quando de sua leitura (há trechos memoráveis, diga-se de passagem, que podem levar o leitor às gargalhadas ou afundá-lo no constrangimento). O próprio autor hesita e se declara inseguro em diversos momentos de sua argumentação. Mas por que Thalassa provoca tais reações? Será por ele descrever o ato sexual com riqueza de detalhes, relatando movimentos, sensações e secreções, além de interpretá-los segundo pontos de vista inacreditáveis? Ora, Hipócrates já fazia isso. Ele não apenas descrevia o coito, como o comparava a uma pequena epilepsia e o esperma a um tipo de espuma (Foucault, 1984). Contudo, não há como ignorar: fora de certas literaturas, este conteúdo não é usual. E mais: o próprio Ferenczi afirma que a genitalidade e $o$ ato sexual foram deixados em segundo plano não apenas pelas ciências, mas inclusive pela psicanálise (Ferenczi, 1924/1990).

Talvez devamos acrescentar, além dessa explicação, que o texto comporta também noções e conceitos que se encontram "exilados" do vocabulário psicanalítico contemporâneo - palavras que, só de serem lidas por um psicanalista do século XXI, já o fazem torcer o nariz e abandonar o livro: fase anal, filogênese, trauma do nascimento, enfim, uma seleção de expressões que foram proscritas nas últimas décadas. Ora, Thalassa foi publicado em 1924. É preciso ter presente o fato de que noventa anos nos separam deste livro que, ao contrário de boa parte da obra freudiana, não passou por releituras. Isto o torna de certa maneira um sítio onde surpreendemos ruínas, carcaças e escombros de um idioma que se transformou muito desde então. 
Enfim, é muito provável que essas duas explicações sejam suficientes para justificar o caráter estranho do ensaio. No entanto, sugerimos adicionar outra explicação: Thalassa abala algumas formas habituais do pensar e, neste gesto mesmo, nos desafia a pensar de modo diferente. Em outras palavras, este ensaio exige sairmos da zona de conforto e convida a entrarmos em uma zona de suspensão, onde o solo não é firme e as condições nos são pouco familiares. Propomos, nas linhas que seguem, sustentar esta hipótese indicando algumas das provocações que Ferenczi leva a cabo - o que só pode ser feito com a apresentação das teses gerais do texto.

\section{Algumas características inabituais do pensamento ferencziano em Thalassa}

Para começar, tomemos o título do livro ${ }^{2}$. Observando-o atentamente, podemos destacar a presença do termo Versuch, que em português foi traduzido por "ensaio". Thalassa é um ensaio. Sendo um ensaio, Thalassa é um texto experimental, um livrolaboratório, onde são realizadas experiências de pensamento e testadas hipóteses que levam, não raras vezes, a linhas extremas de raciocínio. Desafiam-se formas habituais de pensamento e protocolos lógicos, haja vista que o trabalho se desenrola segundo matizes próprios do inconsciente (que, como sabemos, podem contrariar determinadas formas de racionalidade). Ainda que seja o ponto de convergência de muitos achados psicanalíticos e de ideias anteriormente imaginadas, o livro não pretende arrolar uma exposição destes achados e nem sistematizá-los em uma grade conceitual estável. Sendo um ensaio, Thalassa não está voltado tanto para a teoria corrente quanto para o horizonte, isto é, para o que a teoria pode se tornar. Assim, longe de ser um movimento de consolidação teórica, é um processo de germinação instável e irregular. Seu caráter não é de concentração, mas de dispersão. O que é curioso, no entanto, é que isso não se faz sem grande rigor teórico por parte do autor.

Uma das dificuldades inerentes à leitura de Thalassa reside, ainda, no próprio estilo de escrita e de abordagem de problema empreendidos por Ferenczi: ele nos convida a ver as coisas não somente a partir de um prisma diferente, mas também de múltiplos e distintos pontos de vista. Neste sentido, o autor percorre diversas linhas de investigação que se enroscam, se dispersam, se concentram e se prolongam para fora, desorientando assim um modo de pensar que privilegie 0 desenvolvimento de uma única linha de raciocínio. É um pensamento múltiplo e errante. Um pensamento que testa hipóteses, que faz colagem de imagens, que puxa símbolos pelo anzol e que, de tanta informação que acumula, abandona uns e mantém em suspensão 
outros para prosseguir com os escolhidos; um pensamento, além disso, que salta milhas para frente, depois caminha para trás, pega um atalho num lado e embrenha no outro. Se consegue se achar ou, pelo contrário, se perder - quem pode dizer?

Além disso, estamos muito acostumados, quando vamos resolver um problema teórico, a manter nosso pensamento ocupado dentro de um campo - campo este com delimitações claras - e a trabalhar unicamente com os elementos que estão contidos no mesmo. Ferenczi nos convida, pelo contrário, a transitar por diversos espaços, sem levar em consideração os limites que os dividem e os distinguem. Se não há dúvida de que ele reconhece a heterogeneidade dos elementos sobre os quais se debruça - quer dizer, se ele enxerga as diferenças que os separam -, não é menos certo que ele se sente progressivamente à vontade em costurá-los com as múltiplas linhas que traça, fazendo, algumas vezes, relações estranhas, outras vezes, espantosas, mas todas igualmente engenhosas. Estas relações transformam-se, em determinados momentos, em verdadeiros paradoxos que não apenas desrespeitam o bom senso, como provocam uma tensão - a tensão de não oferecer uma resposta simples, uma solução linear, a um determinado problema. Distintamente, tais relações paradoxais concentram, em sua enunciação mesma, sentidos contrários e que, no entanto, convivem forçosamente juntos (Deleuze, 1968/1974).

É preciso frisar: o pensamento de Ferenczi é marcado pelo "entre", pelas relações. E a forma como se dão estas relações é através da mistura, da amalgamação, da anfimixia. Não obstante, é necessário destacar que as misturas que formam a base da experimentação ferencziana não têm, inequivocamente, um tom conciliatório, se por conciliação entendemos apaziguamento de ânimos e harmonização de dissonantes. Se, por outro lado, por conciliação entendemos articulação ou combinação de coisas - sem que isso tire a possibilidade de diferença, tensão e violência entre elas - então nada temos a protestar. As misturas em Ferenczi podem ter, certamente, pacificações - mas também (e principalmente) vitalidade, movimento e desacordo. As misturas transformam a maneira de ser das coisas que estão em relação e para elas produzem efeitos, ainda que sejam (as misturas e os efeitos) por demais transitórios e evanescentes. Pensar por misturas implica em destituir a concretude das fronteiras e, neste sentido, escapar de uma lógica de "ou isto ou aquilo". Descortina-se, com esta destituição, uma zona de indeterminação, onde se considera "tanto isto quanto aquilo", pois furtar-se de levar em conta um ou outro não nos leva muito mais longe do que poderíamos (Câmara \& Herzog, 2014).

Esse estilo de pensamento, que incomoda alguns hábitos que estão na base da nossa maneira de pensar, se materializa de modo emblemático em um conceito que Ferenczi constrói na tentativa de 
formalizar um método. Dizemos "formalizar" porque ele, Ferenczi, credita a autoria deste método à Freud. A seu ver, a única contribuição que teve foi o de dar um nome e, vale dizer, radicalizá-lo a um ponto desmedido, se comparado ao modo como Freud o utilizou. Ferenczi chama de utraquismo o método que consiste em abrir um espaço de intercâmbio entre a psicanálise e outras ciências visando trazer movimento e fôlego para o trabalho metapsicológico, principalmente quando se busca realizá-lo em regiões teóricas engessadas ou pouco desenvolvidas (Câmara \& Herzog, 2014; Câmara, Herzog, Pinheiro, Verztman, Pacheco-Ferreira, Viana, 2016). Será a partir desta experimentação metodológica, onde a psicanálise transborda sobre a biologia e vice-versa, que Ferenczi perseguirá o seu objetivo em Thalassa: construir uma teoria que forneça os múltiplos sentidos da genitalidade (Ferenczi, 1924/1990).

Em outras palavras, o utraquismo consiste em um programa de esmaecimento das fronteiras que separam a psicanálise da biologia e as ciências do espírito das ciências da natureza, para constituir, em seu lugar, um limiar, uma zona intermediária onde os elementos pertencentes a ambas as disciplinas transitam com liberdade, contaminando-se e imunizando-se, produzindo tensões e harmonizações, construindo estruturas de figuras e complexidades variáveis que logo se desmontam e se rearranjam de outra maneira. É nesta zona que Ferenczi monta o seu laboratório e inicia as suas experimentações que serão apresentadas em Thalassa: experiências que consistem propriamente em decomposições e misturas, em injeção de noções da psicanálise a teorias biológicas e vice-versa, em produção de criaturas híbridas belas e patéticas.

Neste laboratório, nasce, por exemplo, uma teoria da evolução que junta Lamarck, Darwin e Freud, posto que as teses da seleção natural e da adaptação não possam, sozinhas, entender o processo evolutivo sem levar em conta a força imanente do desejo; ou ainda, uma teoria do símbolo que, longe de se apoiar em uma ideia transcendentalista de "inconsciente coletivo", se fundamenta em uma perspectiva radicalmente corporal de "inconsciente biológico", onde a gênese de um símbolo está vinculada à maneira singular pela qual uma estrutura biológica se formou e evoluiu ao longo da história como tentativa de escapar das catástrofes; ou, ainda, uma teoria "mais ou menos fisiológica" da sexualidade, na qual os conceitos de deslocamento e condensação, fundamentais para a compreensão do trabalho do sonho, são vertidos para a compreensão da sexualidade. Sexualidade que é, por sua vez, entendida como uma "polimorfia" de fusões de erotismo (Ferenczi, 1924/1990). Uma fisiologia onírica. 


\section{0 conceito de anfimixia dos erotismos}

A propósito desta última teoria, vale dizer que, já nos dois capítulos iniciais de Thalassa, Ferenczi propõe uma visão muito particular da maneira como se dá o desdobramento da sexualidade. Sua apreciação é muito instrutiva, haja vista ela "simbolizar" (ou "autosimbolizar"), de certa maneira, o estilo de pensamento que estamos descrevendo - um pensamento por misturas. O conceito que ele forja para manejar sua perspectiva acerca da sexualidade é o conceito de anfimixia, que significa algo como "mistura de um lado e de outro" ou "mistura de ambos os lados" (Figueiredo, 1999). A anfimixia consiste no processo através do qual diferentes modos de erotismo podem se misturar, inventando assim uma nova modalidade de erotismo. Longe dos dois componentes se perderem e se converterem em uma síntese, a formulação de Ferenczi é bem específica: apesar de dois erotismos se misturarem, eles não perdem seu "caráter próprio"; eles emprestam, isso sim, suas qualidades ao novo erotismo, que passa a englobar, em si, as qualidades dos dois erotismos que se juntaram (Ferenczi, 1924/1990). No novo erotismo, em suma, pulsam e convivem os erotismos anteriores, com todas as diferenças que eles possam ter.

É a partir destes parâmetros que Ferenczi vislumbra a maneira do primado do genital se formar. Longe dos autoerotismos superados sobreviverem somente como formas de preparação para o ato sexual, eles delineiam o ritmo, as velocidades, os vetores, os movimentos e os intervalos que configuram a genitalidade. O erotismo uretral empresta as qualidades de precipitação e emissão, enquanto o erotismo anal determina as qualidades de paragem e retenção. 0 erotismo oral, por sua vez, confere o ritmo dos movimentos que são desencadeados no coito. A mistura destes três modos no erotismo genital confere ao mesmo graus variáveis de precipitação, retenção e ritmo - graus variáveis que dependem da quantidade de que cada modo de erotismo foi empregada. A geometria dos erotismos misturados desenvolve, neste sentido, a coreografia da dança que o genital e o corpo empreendem durante $o$ ato sexual. Assim, por exemplo, se dos ingredientes da mistura há uma predominância do erotismo anal, então o sujeito retém por mais tempo o esperma e adia, consequentemente, a ejaculação. O oposto ocorre quando 0 erotismo uretral prevalece. Se essa desigualdade na mistura atinge graus excessivos, então o sujeito pode ter sua potência genital ameaçada ${ }^{3}$ (Ferenczi, 1924/1990).

A anfimixia não ocorre apenas na constituição do primado do genital. A criança se revela uma exímia alquimista dos erotismos, na medida em que inventa, ao longo da infância e para além dela, novas formas de obter prazer cada vez que se vê impedida de manter uma modalidade que já domina. O que viria a impedi-la disso, senão a 
educação imposta pelos adultos? Vejamos, por exemplo, a criança que obtém prazer de urinar intempestivamente assim que lhe dá vontade (erotismo uretral) e de reter as fezes para despejá-las somente segundo circunstâncias especiais (erotismo anal). Faz parte da educação (do treino do asseio) ela ser capaz de adaptar os seus hábitos excretórios de acordo com os momentos estipulados pelos adultos. Para isso, a criança precisa renunciar ao prazer envolvido na execução dos seus hábitos singulares e afirmar o desprazer imposto pela educação, aderindo para si, neste processo, novos hábitos que condizem mais com o comportamento exigido pela sociedade. Segundo os termos teóricos de Ferenczi, há neste processo uma anfimixia: o erotismo uretral mistura-se com o erotismo anal, de modo que agora a criança obtém prazer ao segurar a urina. O mesmo ocorre em relação ao erotismo anal: ao combinar-se com o uretral, a criança passa a ter satisfação a cada vez que excreta suas fezes (Ferenczi, 1924/1990). Neste sentido, para a criança nada é de graça: ela somente afirma um desprazer se conseguir inventar outra forma de obtenção de prazer que compensa, por sua vez, o prazer que precisou ser renunciado.

\section{A interpretação do ato sexual com base na ideia de regressão}

Conforme sustentamos, as construções teóricas de Ferenczi em Thalassa desafiam hábitos arraigados de pensamento, convocandonos a encontrar outras maneiras de pensar. Uma das perspectivas a partir da qual Ferenczi descreve propriamente o ato sexual é suficiente para mostrar a que ponto seu pensamento, ao transgredir fronteiras e operar misturas, sai de uma lógica dicotômica. Para isso, pensemos por um momento que não há um muro entre o eu e o outro, mas um limiar, uma zona de transição indiferenciada entre estes dois polos, onde cada um deles transborda sobre o outro. E, ao mesmo tempo, retenhamos, também, a ideia de que os limites que separam as gerações podem ser transpostos sem grandes resistências, de forma que o eu pode virar mãe e vice-versa. $E$, simultaneamente, saibamos que o eu pode se tornar não apenas outro humano, mas também um animal de outra espécie (como um peixe), um órgão corporal (pênis, útero), uma substância (excremento, sêmen) ou até mesmo uma paisagem, um meio ambiente (oceano, terra). E, também, digamos que o tempo, tal como o entendemos, pode se comportar de maneira paradoxal, de forma que ir para frente é ir para trás, e ir para trás se consegue indo para adiante; que um simples ato consumado condensa e repete toda a história individual do sujeito e toda a história evolutiva da espécie e toda a história geológica do mundo - afinal de contas, Thalassa reúne 
três linhas narrativas que se paralelizam, se entrecruzam e se repetem, ainda que a partir de velocidades e intervalos diferentes: a ontogênese, a filogênese e, entre elas, a perigênese.

Tomemos, pois, uma das descrições que Ferenczi (1924/1990) faz acerca do coito (heterossexual e segundo o ponto de vista do homem). $O$ homem se identifica com seu órgão genital. $O$ homem se torna pênis. O homem entra em contato sensorial com a mulher, sentindo-se atraído pela mesma e desejando unir-se com ela. Através do contato físico, que se dá predominantemente pelo tato - beijo e abraço, por exemplo -, o homem identifica-se com o corpo da mulher. (É preciso fazer isso: como pode o homem inserir o seu pênis, quer dizer, alojar-se por inteiro, em um ambiente que lhe é estranho? Ele precisa tornar o depositário do pênis, logo de si mesmo, um sítio familiar, um local confiável - enfim, um lugar que seja o prolongamento dele próprio). Assim, há uma mistura do corpo do homem com o da parceira, de modo que ambos se tornam um só corpo. O homem penetra o genital - se penetra integralmente, já que ele é genital - no corpo da mulher que, não obstante, é o seu próprio corpo, e esse corpo da mulher que também é seu, é também o ventre da mãe. Na medida em que o homem penetra o pênis (e ele todo) no corpo da mulher (que é o seu próprio corpo), e ele adentra, neste movimento mesmo, no ventre materno (que também é ele próprio), retorna a um tempo em que era feto - voltando assim a um modo de vida intrauterino - e, de quebra, se transforma no esperma que separou-se de si próprio para reunir-se em si próprio que é o corpo da mãe que é da mulher que é seu. O processo não para por aí: um empuxo filogenético arrasta o feto a uma tal distância e velocidade que ele se converte num Amphioxus lanceolatus, o peixe ancestral de todos os vertebrados, e o ventre se dilata, simultaneamente, até 0 infinito para transformar-se no oceano perdido, que passa a acalentar aquela criatura arcaica. Findo o ato sexual, todo esse intrincado emaranhado de alucinações psíquicas e orgânicas desvanece de forma tão imperceptível como a transição do crepúsculo.

Passemos agora ao comentário desta imagem-movimento. O coito é, através dela, figurado como uma zona intermediária, um estado crepuscular e transitório; um ato que condensa uma rede de identificações que infiltram e invadem diferentes estratos históricos; uma mistura incessante de elementos que, a cada agitação, transforma radicalmente o quadro geral do processo; um violento paradoxo no qual, quanto mais próximo se chega, mais longínquo se torna. Deste paradoxo, um fluxo borbulha incessante: invaginações são invadidas por prolongamentos que por sua vez se invaginam para serem penetrados por novos prolongamentos e assim por diante. Estranha forma de interpretar o ato sexual! Ela consiste na mobilização radical de certas teses psicanalíticas, como o Édipo, a regressão, a identificação e a transferência. Da mesma forma, é uma 
aplicação ousada da forma como seu autor concebe o amor: "o homem", diz Ferenczi (1912/1991), "só pode amar-se a si mesmo e a mais ninguém; amar a outrem equivale a integrar esse outrem no seu próprio ego" (p. 181). Neste sentido, tal forma de representar o ato sexual talvez seja, no final das contas, apenas uma forma exótica, e quem sabe pitoresca, de explicitar o caráter narcísico do amor, que exige a introjeção do outro no eu para que este outro possa ser amado.

É importante salientar que não é apenas na fase genital que essas estranhas misturas têm lugar. Após o trauma do desmame, portanto, na fase anal, a criança, sem poder contar com a mãe para satisfazer seus impulsos eróticos, torna-se ela mesma a mãe; e as suas fezes, que estão em suas entranhas, tornam-se a própria criança: agora, a criança está mais uma vez no útero da mãe, a partir do momento em que o útero da mãe é o seu próprio intestino e as fezes, a própria criança. O mesmo ocorre na fase da masturbação (ou, segundo designação de Freud, fase fálica): a criança se torna o pênis e a mão (da criança) se torna a mãe (Ferenczi, 1924/1990). Uma vez mais a criança retorna ao ventre materno - tudo isso na palma de sua mão. Mas por que isso? Por que essa insistência em retornar à vida intrauterina? Antes de respondermos a isso, salientemos que, em Ferenczi, as misturas que rompem com a imagem de um sujeito bem delimitado por fronteiras estão presentes ao longo de toda sua escrita. Vide a criança que só é capaz de obedecer aos pais ao se tornar propriamente os pais (Ferenczi, 1909/1991). Ou o pequeno Árpad, que se torna pintinho, depois galinha e, por fim, galo: o pequeno homem-galo. $\mathrm{E}$, diante de seu bico e de suas penas, todo 0 cosmo se transforma em um galinheiro, toda a humanidade, em criaturas galináceas (Ferenczi, 1913/1992). Ou vide ainda a criança que, à força do descrédito que desmente um trauma sofrido, torna-se ela própria aquele que a agrediu (Ferenczi, 1933/1992). E não nos esqueçamos que a análise mútua, esta experiência técnica que se encontra incluída em uma série na qual perfilam a contratransferência, a telepatia e a transmissão de pensamentos, também figura outra forma de mistura: a mistura de inconscientes do analista e do analisando (Ferenczi, 1932/1990).

Feita esta pequena digressão, retomemos a questão acima ventilada: por que a obstinação em regressar ao corpo da mãe? Ferenczi postula que uma força impele todo 0 ato sexual genital e também prégenital: a pulsão de regredir ao ventre materno, ao modo de vida intrauterino e, ao mesmo tempo, a uma época anterior ao trauma do nascimento. "Desejo" este soberano, que atesta um princípio edipiano nos processos biológicos ou, pelo contrário, que apresenta uma tendência biológica universal da qual o desejo edípico é somente uma de suas expressões (Ferenczi, 1924/1990). Mas, também, outra força impulsiona esta primeira: a pulsão da espécie de retornar ao oceano 
perdido (Thalassa), ao modo de vida aquático e, sempre ao mesmo tempo, a um mundo anterior à catástrofe da seca dos oceanos. $\mathrm{Na}$ verdade, todas as catástrofes que ameaçaram a espécie e que a forçaram a evoluir - e, portanto, a aumentar sua história filogenética - se repetem e são superadas durante o ato sexual (Ferenczi, 1924/1990). "Superadas" no sentido do sujeito lograr atingir uma época em que essas catástrofes ainda não haviam acontecido (neste caso, a superação equivale à regressão).

As catástrofes são rupturas; elas instauram descontinuidades e abismos onde antes era um fluxo. Na medida em que elas ocorrem, elas criam um tempo - um antes e um depois - e um "desejo" partir do depois para chegar ao antes. Onde há catástrofe e trauma o "desejo" há de advir. Esse "desejo" (sempre entre aspas) é o de regressar para onde se foi expulso, é o de atravessar a catástrofe e, portanto, voltar para um estado anterior às condições que, em primeiro lugar, fizeram nascer o "desejo" que ora pulsa. É assim que o nascimento é um trauma: a uma existência intrauterina e monádica, onde não havia eu e não-eu, impõe-se agora uma existência extrauterina, na qual progressivamente - devido a rupturas no sentimento de onipotência e a partir de um jogo oscilatório de introjeções e projeções -, forma-se ao mesmo tempo um eu, um não-eu e, entre eles, uma fronteira (Ferenczi, 1909/1991). Todo movimento de regressão é um retorno a estágios cada vez menos compartimentalizados, a épocas da vida em que as fronteiras que limitam e definem se esmaecem até não existirem mais, a épocas, portanto, anteriores às catástrofes. Estas experiências de regressão atestam que mesmo as distinções que orientam o nosso mundo são construídas historicamente e podem ser suspensas: o coito, mas também o sono, são oportunidades para essa suspensão.

\section{A interpretação do ato sexual com base em uma "fisiologia" do prazer e na ideia de repetição}

A concepção de ato sexual tal como apresentada acima se dá segundo um ponto de vista "histórico-genético". Se isso já não bastasse, Ferenczi (1924/1990) interpreta o coito, ainda, conforme o aspecto que ele denominou como "descritivo-econômico". Conforme se pode depreender, o desenvolvimento de seu pensamento não é linear. Mais parece um pensamento errante que, baseando-se em ângulos insólitos, mira para todos os lados e desvia de uma trajetória tão logo ela se mostra por demais estável. O ponto de vista históricogenético procura lançar luz sobre a série mnêmica que acumula todos os trilhamentos históricos escondidos por detrás do ato sexual, dirigindo-o para certas potencialidades e inscrevendo todas as suas 
conformações anteriores. (Vale dizer que todos os processos, e não apenas o coito, são culminações de uma multiplicidade de longas histórias marcadas no chamado inconsciente biológico). A perspectiva descritiva-econômica, por sua vez, é uma leitura da série atual, que busca interpretar quais os processos orgânicos que ocorrem e concorrem para o coito (Ferenczi, 1924/1990). Em outras palavras, ela não lida tanto com a pulsão que deseja regredir, mas com os intrincados mecanismos de prazer, angústia e compensação que atuam no e para o ato sexual.

Imaginemos - ou melhor, lembremos, já que o que será dito é declarado pelo próprio Freud (1914/2010) em seu trabalho sobre o Narcisismo -, que todos os órgãos do corpo, e não só as zonas erógenas, produzem, no próprio exercício de suas funções, excitação sexual. A excitação sexual precisa ser descarregada, de acordo com o princípio do prazer o qual, para a visão monista de Ferenczi, rege tanto os processos psíquicos quanto orgânicos. Se os órgãos virem a se satisfazer de maneira autoerótica, este processo interferirá, então, em suas funções, inutilizando o órgão ${ }^{4}$. Para Ferenczi, toda a excitação produzida pelos órgãos é enviada (ou tende a ser enviada) para o órgão genital (Ferenczi, 1919/1993; 1924/1990). A função deste último é armazenar e concentrar em si a excitação para ele deslocada e, periodicamente, descarregá-la. A ereção, e depois a fricção do pênis no canal vaginal, são manifestações claras da tensão que, acumulada, se torna cada vez mais insuportável de ser mantida: tanto a ereção quanto a fricção são tentativas violentas do homem arrancar de si o pênis, este órgão que irradia sensações de tensão tão elevadas (Ferenczi, 1924/1990). Neste sentido, o homem é um autocastrador, mas um autocastrador fracassado, haja vista ele não ser bem sucedido no empreendimento de separar-se do pênis (Câmara et al., 2016). A maneira como este último logra, enfim, se desembaraçar do crescente volume de tensão é pela ejaculação: na medida em que o esperma se separa do resto do organismo, tem-se uma descarga súbita e maciça da tensão. A descarga produz uma onda de satisfação que percorre todos os órgãos, satisfazendo assim suas exigências individuais de satisfação. Consequência: sentimento global de felicidade e, ao mesmo tempo, quase completo esvanecimento da consciência. Eis o orgasmo.

Ainda que seja tentador dar por concluída essa perspectiva, Ferenczi a coteja apelando para uma mistura com o ponto de vista "históricogenético". Contudo, sua preocupação não está mais focada no trânsito de excitações e nem nos percalços do desejo de regressão, mas em um tema correlato: a repetição. Ao observar as sensações psíquicas que o sujeito experimenta durante o coito, ele delimita precisamente duas: o ato sexual é impregnado, em um primeiro momento, pelo afeto de angústia e, em sequência, pela sensação de prazer (Ferenczi, 1924/1990). A angústia, que se manifesta pelos 
sintomas cardiorrespiratórios conhecidos, repete a reação frente ao trauma do nascimento, mas também à catástrofe da seca dos oceanos e, como já é de se esperar, de todas as outras catástrofes pelas quais a espécie foi forçada a atravessar e que, com efeito, conseguiu sobreviver. Neste sentido, o coito repete todas as catástrofes e, ao mesmo tempo, todas as lutas que a espécie travou para se adaptar aos novos modos de vida impostos pelo ambiente modificado por tais catástrofes: por exemplo, o bebê que, após o nascimento, deve respirar com seus pulmões e o animal aquático que, sendo lançado ao ambiente terrestre, deve adaptar seu aparelho respiratório para capturar o oxigênio atmosférico. Na medida em que a repetição não se limita à experiência do trauma, mas também à sua superação (aqui, superação equivale à progressão, na medida em que foi possível adaptar-se para um novo modo de vida conforme imposto pelo trauma), Ferenczi (1924/1990) lança mais uma interpretação: a cada ato sexual realizado o sujeito abreage um pouco da excitação traumática que pulsa em seu corpo - excitação esta que não se resume, bem entendido, apenas ao resíduo deixado pelo trauma do nascimento e outros traumas ontogenéticos, mas também oriundo de todas as demais catástrofes sofridas ao longo da linha evolutiva.

O fato de o sujeito repetir a superação do trauma leva Ferenczi a descrever a sensação de prazer experimentada no coito como uma "festa comemorativa" que celebra o êxito da adaptação e da sobrevivência do indivíduo e da espécie. Para coroar esta folia, o ato sexual é concluído pela negação e consequente esquecimento da catástrofe e da angústia que foi até há pouco repetida e vivida. Se, aos seus olhos, para Freud é indecidível determinar se a repetição traumática é pura compulsão sem prazer, ou se nela algum quinhão de prazer está envolvido, Ferenczi não hesita: a repetição traumática - ao menos conforme comparece no ato sexual - é uma coisa e outra, quer dizer, ela implica necessariamente, por um lado, uma dimensão compulsiva, e por outro, uma dimensão de prazer (Pinheiro, 1995). Afinal de contas, repete-se não somente o trauma, como também o triunfo sobre ele; é revivido não apenas a angústia sofrida ante a situação catastrófica, como também o prazer de ter sobrevivido a ela, o prazer de ter abreagido um pouco de sua excitação, enfim, o prazer do sujeito ter ativamente esquecido de sua experiência.

\section{A noção de erotismo lúdico e a radicalização do papel do prazer}

O caráter paradoxal da compulsão à repetição - reprodução mecânica do trauma e revivescência prazerosa de sua superação - leva Ferenczi a compor uma visão muito particular, para não dizer 
original, sobre o erotismo: há um caráter essencialmente lúdico no erotismo. O sexo é uma brincadeira. Assim como as crianças escutam uma mesma história repetidas vezes - como se fosse a primeira vez mas, paradoxalmente, censurando qualquer alteração que se faça no enredo já conhecido (Freud, 1920/1940) -, o ato sexual encena também, todas as vezes, a mesma história: uma crise se instala e, com ela, uma enorme angústia. Entretanto, esta situação difícil é resolvida e tudo acaba por terminar bem. Esta é a dimensão lúdica do erotismo: repete-se o trauma e as catástrofes, e com eles a angústia correlata, mas apenas com a certeza de que vai se sobreviver a elas e comemorar o desfecho feliz. "Logo", conclui Ferenczi (1924/1990), "a sexualidade não faz mais do que brincar com o perigo" (p. 52, grifos no original). A bem da precisão, é somente por ser capaz de projetar no futuro o "final feliz" do coito, e ter seguro que esta expectativa vai se concretizar, que o sujeito consegue se entregar a uma repetição angustiante do trauma. Se o prêmio por esta travessia é o júbilo de ter sobrevivido ao trauma (a "festa comemorativa"), não se deve esquecer que o outro motor da repetição é a exigência de abreagir, a conta-gotas, o resíduo traumático não-liquidado das catástrofes individuais e supra individuais - abreação esta que só pode se dar pela própria repetição do trauma.

Diante desta função importante de abreação do trauma, devemos entender que a dimensão do prazer da repetição está a ela subordinada? Não. O prazer é tão fundamental quanto aquela função. Ambos são protagonistas. A importância do caráter lúdico do ato sexual reside no fato de que, com ele, o sujeito (e qualquer organismo) pode, enfim, relaxar das árduas e exaustivas tarefas da existência, o que significa não apenas o festim comemorativo, como também a possibilidade de recolher-se em um abrigo, em um lugar de descanso (Ferenczi, 1924/1990). Sabemos que Ferenczi vê neste lugar não tanto a morte quanto o ventre materno - ou melhor, vê tanto um quanto o outro, e ainda o sono e demais atividades que possam entrar em relação analógica com as referidas. Para ele, no entanto, o descanso - seja ele qual for - não representa uma abolição de excitações. No interior do útero materno, por exemplo, se a criança é protegida de qualquer estimulação, ela ainda assim faz uma coisa: ela cresce. Do mesmo jeito, no coito e no sono o organismo cresce, regenera e revitaliza. E mesmo na morte, por fim, grassam flutuações de energia vital no seio mesmo do material inorgânico (Ferenczi, 1924/1990).

É preciso, pois, que deixemos assinalada a importância do prazer em Thalassa. O prazer integra fundamentalmente a repetição. A invenção de uma nova forma de obtenção do prazer é a condição essencial para a compensação de todas as atividades prazerosas que devem ser renunciadas em favor da afirmação do desprazer. O prazer, enfim, deve ser um paradigma tanto quanto o é o utilitarismo nas 
ciências da vida: deve-se estudar a anatomia, a fisiologia e a patologia não apenas por um viés utilitário, mas também segundo um ponto de vista que leve em conta o prazer dos órgãos e demais estruturas biológicas (Ferenczi, 1919/1993; 1924/1990). Ora, o modo como Ferenczi defende a importância do prazer talvez não seja inútil para nós, a partir do momento em que nos possibilite reconsiderar o papel do prazer na dinâmica de funcionamento dos pacientes contemporâneos - papel este que, sem dúvida, foi muito esvaziado ou, ao menos, relegado a um plano secundário. Mas talvez seja importante também, para propósitos mais imediatos e menos ambiciosos, que a questão do prazer nos sensibilize quando nos propomos a realizar 0 ato de ler ou reler Thalassa. Se o recebemos com hospitalidade - dando-lhe tempo para se expressar e buscando compreendê-lo para além de suas gagueiras, precipitações e vacilações -, talvez tenhamos a oportunidade de uma leitura prazerosa, uma experiência lúdica, e até mesmo, quem sabe, a possibilidade de entrar em contato com outras perspectivas e modos de pensar.

\section{Referências}

Balint, M. (1987). Thrills and regressions. London: Maresfield Library. (Trabalho originalmente publicado em 1959).

Balint, M. (2014). A falha básica: aspectos terapêuticos da regressão. São Paulo: Zagodoni. (Trabalho originalmente publicado em 1967).

Birman, J. (2014). Arquivo e memória da experiência psicanalítica: Ferenczi antes de Freud, depois de Lacan. Rio de Janeiro: Contra Capa.

Câmara, L. \& Herzog, R. (2014). Um e outro: Ferenczi e a epistemologia. Psicologia USP, 25(2), 125-133.

Câmara, L., Herzog, R., Pinheiro, T., Verztman, J., Pacheco-Ferreira, F., Viana, D. (2016). Autotomie et clivage: de l'image au concept. Revue Canadienne de Psychanalyse, 24(2), 103-117.

Deleuze, G. (1974). Lógica do sentido. São Paulo: Perspectiva e Editora da USP. (Trabalho originalmente publicado em 1968).

Espinosa, B. (2012). Breve tratado de Deus, do homem e do seu bem-estar. Belo Horizonte: Autêntica Editora.

Ferenczi, S. (1990). Diário clínico. São Paulo: Martins Fontes. (Trabalho originalmente publicado em 1932).

Ferenczi, S. (1990). Thalassa: ensaio sobre a teoria da genitalidade. São Paulo: Martins Fontes. (Trabalho originalmente publicado em 1924). 
Ferenczi, S. (1991). O conceito de introjeção. In Psicanálise I (pp. 181-3). São Paulo: Martins Fontes. (Trabalho originalmente publicado em 1912).

Ferenczi, S. (1991). Transferência e introjeção. In Psicanálise I (pp. 77-108). São Paulo: Martins Fontes. (Trabalho originalmente publicado em 1909).

Ferenczi, S. (1992). Confusão de língua entre os adultos e a criança. In Psicanálise IV (pp. 97-106). São Paulo: Martins Fontes. (Trabalho originalmente publicado em 1933).

Ferenczi, S. (1992). Um pequeno homem-galo. In Psicanálise II (pp. 61-7). São Paulo: Martins Fontes. (Trabalho originalmente publicado em 1913).

Ferenczi, S. (1993). Fenômenos de materialização histérica. In Psicanálise III (pp. 41-53). São Paulo: Martins Fontes. (Trabalho originalmente publicado em 1919).

Figueiredo, L. C. (1999). Palavras cruzadas entre Freud e Ferenczi. São Paulo: Editora Escuta.

Foucault, M. (1984). História da sexualidade 2: o uso dos prazeres. Rio de J aneiro: Edições Graal.

Freud, S. \& Ferenczi, S. (1996). The correspondence of Sigmund Freud and Sándor Ferenczi (vol. 2, 1914-1919). Cambridge: Harvard University Press.

Freud, S. (1940). Jenseits des Lustprinzips. In Gesammelte werke (band 13, pp. 1-69). London: Imago. (Trabalho originalmente publicado em 1920).

Freud, S. (2010). Introdução ao narcisismo. In Obras completas (Paulo César de Souza, trad., vol. 12, pp. 13-50). São Paulo: Companhia das Letras. (Trabalho originalmente publicado em 1914).

Freud, S. (2011). Sándor Ferenczi. In Obras completas (Paulo César de Souza, trad., vol. 18, pp. 465-8). São Paulo: Companhia das Letras. (Trabalho originalmente publicado em 1933).

Freud, S. (2013). Concepção psicanalítica do transtorno psicogênico da visão. In Obras completas (Paulo César de Souza, trad., vol. 9, pp. 313-323). São Paulo: Companhia das Letras. (Trabalho originalmente publicado em 1910).

Jones, E. \& Balint, M. (2004). Correspondance Ernest Jones/Michael Balint Avril 1938-Janvier 1958. Le Coq-héron, 177(2), 25-88.

Pinheiro, T. (1995). Ferenczi: do grito à palavra. Rio de Janeiro: Jorge Zahar Ed.; Ed. UFRJ .

Torok, M. (2001). Catastrophes [Katasztrófak] Lettre ouverte sur la correspondance de Freud avec Ferenczi. In J. C. Rouchy (Org.). La psychanalyse avec Nicholas Abraham et Maria Torok (pp. 813). Toulouse: ERES. 


\section{Endereço para correspondência \\ Leonardo Cardoso Portela Câmara}

Universidade Federal do Rio de J aneiro - UFRJ

Programa de Pós-Graduação em Teoria Psicanalítica

Av. Pasteur, 250 fundos, Pavilhão Nilton Campos, Urca, CEP 22290-240, Rio de Janeiro - RJ, Brasil

Endereço eletrônico: Icpcamara@gmail.com

\section{Regina Herzog}

Universidade Federal do Rio de J aneiro - UFRJ

Programa de Pós-Graduação em Teoria Psicanalítica

Av. Pasteur, 250 fundos, Pavilhão Nilton Campos, Urca, CEP 22290-240, Rio de Janeiro - RJ, Brasil

Endereço eletrônico: rherzog@globo.com

Recebido em: 13/04/2016

Aceito em: 06/08/2017

\section{Notas}

* Psicanalista, mestre e doutorando em Teoria Psicanalítica (UFRJ), bolsista pela CAPES.

** Psicanalista, professora associada do PPGTP/IP/UFRJ, coordenadora do NEPECC (Núcleo de Estudos em Psicanálise e Clínica da Contemporaneidade), bolsista de produtividade em pesquisa do CNPq.

1 Os outros dois livros foram Histeria e patoneurose (1919) e Conferências populares sobre psicanálise (1922). Ferenczi também participou com um dos capítulos de um livro editado em conjunto, Psicanálise das neuroses de guerra (1919).

${ }^{2} \mathrm{O}$ título original é simplesmente Versuch einer Genitaltheorie ("Ensaio sobre a teoria da genitalidade"). "Thalassa", o termo grego que designa oceano, é adicionado ao título somente na terceira tradução do livro, a versão americana de 1933-4, ficando Thalassa: a theory of genitality ("Thalassa: uma teoria da genitalidade"). A versão brasileira decidirá por realizar uma mistura entre o título original (e, com isso, a qualificação da obra como um ensaio) e o da edição americana. Uma versão francesa mais atual fez o mesmo, o que significa dizer que abandonou o título da primeira tradução para aquela língua, que foi Thalassa: psychanalyse des origines de la vie sexuelle ("Thalassa: psicanálise das origens da vida sexual"). Uma curiosidade: a segunda tradução do livro, datada de 1929 e matriz para todas as traduções posteriores, foi a húngara, língua materna de Ferenczi. O título dado a esta versão foi Katasztrofàk a nemi müködés fejlödésében, que pode ser traduzido como "Catástrofes na história da evolução da genitalidade", segundo Ferenczi, ou "Catástrofe no desenvolvimento do funcionamento genital", segundo Maria Torok (Torok, 2001).

${ }^{3}$ Frisamos que é a potência genital que é comprometida neste processo. Sendo este o caso, Ferenczi entende que alguma outra forma de erotismo está predominando na economia do prazer. Eis o grande ensinamento da técnica ativa, e, podemos acrescentar, eis a via de ação que ela sugere no processo analítico: a técnica ativa consiste em inventar novas misturas e encorajar sua experimentação.

${ }^{4}$ Basta nos lembrarmos de Freud (1910/2013) mais uma vez, quando interpreta a cegueira histérica como o triunfo da pulsão sexual sobre a pulsão do eu, no âmbito mesmo dos órgãos da visão.

Este artigo de revista Estudos e Pesquisas em Psicologia é licenciado sob uma Licença Creative Commons Atribuição-Não Comercial 3.0 Não Adaptada. 